Information Management and Business Review

Vol. 5, No. 11, pp. 547-552, Nov 2013 (ISSN 2220-3796)

\title{
A Review on Technique in Managing Oil Palm Plantation towards a Digitalized Online 3D Application
}

\author{
Ruzinoor Che Mat*, Abdul Nasir Zulkifli, Norani Nordin, Shahrul Azmi Mohd Yusof \\ Universiti Utara Malaysia, Malaysia \\ *ruzinoor@gmail.com
}

\begin{abstract}
The oil palm industry has been well known as the backbone in Malaysian agriculture and still maintain as the main commodity exports. The research on oil palm industry has been growing gradually by utilizing various methods and technology to solve the problem in managing oil palm plantation. The aim of this paper is to review the technique in managing oil palm plantation towards a digitalized online 3D application. Various problems and techniques on managing oil palm plantation has been reviewed which involving various technology such as GIS, GPS, DBMS and hyperspectral. It was found that monitoring the characteristic of oil palm plantation is beneficial and important to oil palm planters. The new online 3D application for oil palm plantation management has a potential of assisting oil palm managers in making a decision, visualizing their plantation in online 3D environment, and managing their plantation effectively.
\end{abstract}

Keywords: Oil palm, management, online 3D, technique, and digitalized

\section{Introduction}

Malaysia is the largest world producer and exporter of oil palm's product with a 50\% share of world palm oil production and $61 \%$ of exports (Ming \& Chandramohan, 2002). This is followed by Indonesia, Nigeria, Colombia and other countries in leading the product of oil palm in the world. Jalani, Basiron, Darus, Chan, \& Rajanaidu (2002) has investigated the best way to expand the quality of productivity in oil palm in order to increase the oil palm planting in line with the modern technology management strategy. In addition, although the oil palm cultivation using the expertise methods in planting, the management strategies is also acts as an important role to control any damage of the crops caused by the pests or infected by diseases. Recently, the famous diseases affected oil palm cultivation is Basal Stem Rot (BSR), nutrient deficiencies, orange spotting and genetic orange spotting. These diseases are associated with the tree root systems which is need to be monitored more efficiently. In addition, the use of modern management techniques can also help in solving problems in developing a quality management in oil palm plantations. Recently, a novel contribution by Mimos Berhad (MIMOS) and corporation with Felda Agricultural Services Sdn Bhd (FAS) has developed the first digitalized oil palm plantations. The digitalized technology consists of the detector tools such as Sistem Elektro Mekanikal Mikro (MEMS), wayerless semantic technology, grid computing, security and digital knowledge. The concept of digital technology in managing the oil palm plantations can increase the productivity of oil palm in a long term and provide some knowledge to the management and employees in monitoring the oil palm cultivation. Another element can be injected in improving the digitalized technology in managing oil palm plantations with introducing an online $3 \mathrm{D}$ visualization technique for oil palm plantation management.

\section{Literature Review}

Several techniques had been used in managing the oil palm plantation in order to detect any diseases affected on the trees in monitoring and managing the oil palm plantation as well. According to Susanto, Sudharto, \& Purba (2005) investigates that the Basal Stem Rot (BSR) disease that is caused by Ganoderma Boninense fungus has detected using the biological agent control. The technique known as a biological technique used to detect the symptoms of the fungus through the experimental into the cells of the root. Also, Farid, Lee, \& Sciences (2005) examines that BSR disease is also caused by the fungus known as "Tectona Grandis" through their pathogenicity experiment test. Later, the research contribution by Wu et al. (2013) through their pathogenicity experimental testing, detects the Orange Spotting (OS) disease and is also known as Genetic Orange Spotting (GOS) in oil palm trees. The biological experimental techniques has contributes with very high impact to the oil palm plantation in encouraging the implementation of the modern techniques for a better management practice. The studies from Azahar, Boursier, \& Seman (2008) 
has contributed that the BSR disease has been detected using the Geographical Information System (GIS). The GIS technique has the capability to provide the powerful analysis tools for precision agriculture and be able to apply spatial analysis methods in investigating the behavior of BSR disease. The GIS technique is an integration of Database Management System (DBMS) and Global Positioning System (GPS) to provide spatial representation of data and information (Fairhurst, et al., 2003). In year 2011, the researcher is also move towards using GIS technology to gain a better result in managing and monitoring the affected of BSR disease to the oil palm plantations. The previous study by Nelson, Orum, Jaime-Garcia, \& Nadeem (1999) has applied the GIS, GPS and geostatistics aspects to refine cultural management strategies for plant disease control. They also suggested that the information management is a key to improve the management practices in the farm with the combination of the biological and physical aspects of agricultural systems.

Later, Shafri and Hamdan (2009) used airborne hyperspectral imagery through the vegetation indices and red edge technique to detect BSR disease. The vegetation indices are famously used for estimating the crops and vegetation variables using visible and Near Infrared Regions (NIR). While, the red edge technique is placed at the red-near infrared transition in leaf reflectance with capability to gain information in vegetation spectra (Shafri \& Hamdan, 2009). These techniques are successfully used in detecting and mapping the oil palm trees that were affected by the diseases. Further, the novel research in managing and monitoring the condition of the oil palm trees either healthy or diseased can be noticed on time. Next, Markom et al. (2009) has contributed the new method for BSR detection by highlighted to the Artificial Intelligence (AI) approach. They were introduced an Intelligent Electronic Nose System (e-nose) as the front end sensors and artificial neural networks for pattern recognition with ended by classification tasks in differentiating the healthy and affected oil palm trees using odour parameters with highly accuracy rate. The studied has contributed that the e-nose technique is capable to detect the causal agent or element affected by fungus and bacteria of plant disease via a commercial e-nose tool such as Cyranose 320.

The finding contributed by Asraf, Nooritawati, \& Rizam (2012) is also highlighted AI approach in detecting the other diseases in oil palm tree such as nutrient deficiencies in oil palm leaves. The investigation has utilized the vision system and pattern recognition technique using Support vector Machine (SVM) to classify the disease group. The technique used has capability in control the plants disease by visualizing the symptoms displayed by part of the plant such as stem, leaves and fruit. Earlier, Hairuddin \& Mara (2011) has detected the similar disease using image processing technique that is able to represent the symptoms of nutrient disease in oil palm plantation such as nitrogen, potassium and magnesium. The studies has contributed a method to identify the nutrient deficiencies by developing an algorithm to process the captured images via the image segmentation and feature extraction based on nonlinear spatial filtering method. In order to enhance a better management system in oil palm plantations in Malaysia, the investigation has been proposed by Ruzinoor et al. (2010) in managing and monitoring the oil palm plantations using a 3D architecture. The proposed technique is to improve the existing techniques in the literatures towards the digitizing management technique in oil palm plantations via online application. The management system consists of monitoring the color of oil palm leaves for each tree in the crops. Leaf discoloration on oil palms will show that the tree is might be infected by any diseases such as BSR, nutrient deficiencies, orange spotting and genetic orange spotting as been noticed earlier. Therefore, the management system will examine the condition of the oil palm's roots as to ensure that the root system is healthy or infected by any diseases.

In the literatures, Wu et al. (1988) has contributes that the manual 3D studies on the root characterizations into the forest trees. They examines that the development of a root system in the tree is extremely important to evaluate the transportation of the roots system itself as to ensure the optimum plant health or insulated from any disease. Later, Danjon, Sinoquet, Godin, Colin, \& Drexhage (1999) used $3 \mathrm{D}$ as the digitizing device with combination to AMAPmod as to analyst the characteristics of the root architecture. They also provided a very efficient method for measuring the roots using the geometry and topology of the structural roots of trees. Consequently, the digitizing device measures coordinates in a 3D space. The studies into the root system architecture using 3D visualization method were further developed by Lamanda, Dauzat, Jourdan, Martin, \& Malézieux (2008) in developing the architectural model to assess light availability and root bulkiness in coconut trees plantations. In fact, their novel research has contributed an efficient tool for recommending the management system in managing and monitoring the coconut tree plantations in their study area. The literature study on oil palm plantation management has been done by Jourdan (1997). They has contributes a model and simulation on the root 
system of oil palm tree in order to detect the BSR disease using a 3D architecture. The digitizing model has measured the root system characteristics of oil palm crops for 20 years old. Further, Danjon and Reuben (2008) assessed the woody root systems of oil palm tree using a 3D architecture. They support the statement issued by the earliest studies in the literatures that the root system of the tree have particular features and need the specific procedures to solve any other problem or affected diseases related to the plants in the crops. As can be seen, the proposed idea in enhancing the existing management technique to the digitizing management technique in the oil palm plantation areas acts as an initiator approach to be underlined in the supervision. In fact, the development of management system in the plantations touched by 3D architecture has capability in building an efficient approach for a better management practices.

\section{Methodology}

Based on the discussion, it is necessary to develop online 3D visualization technique for oil palm plantation for better management practices. The proposed methodology towards developing the digitilized online 3D application is shown in Figure 1.0. The methodology is divided into three main parts which is data gathering, construction phase and deployment phase.

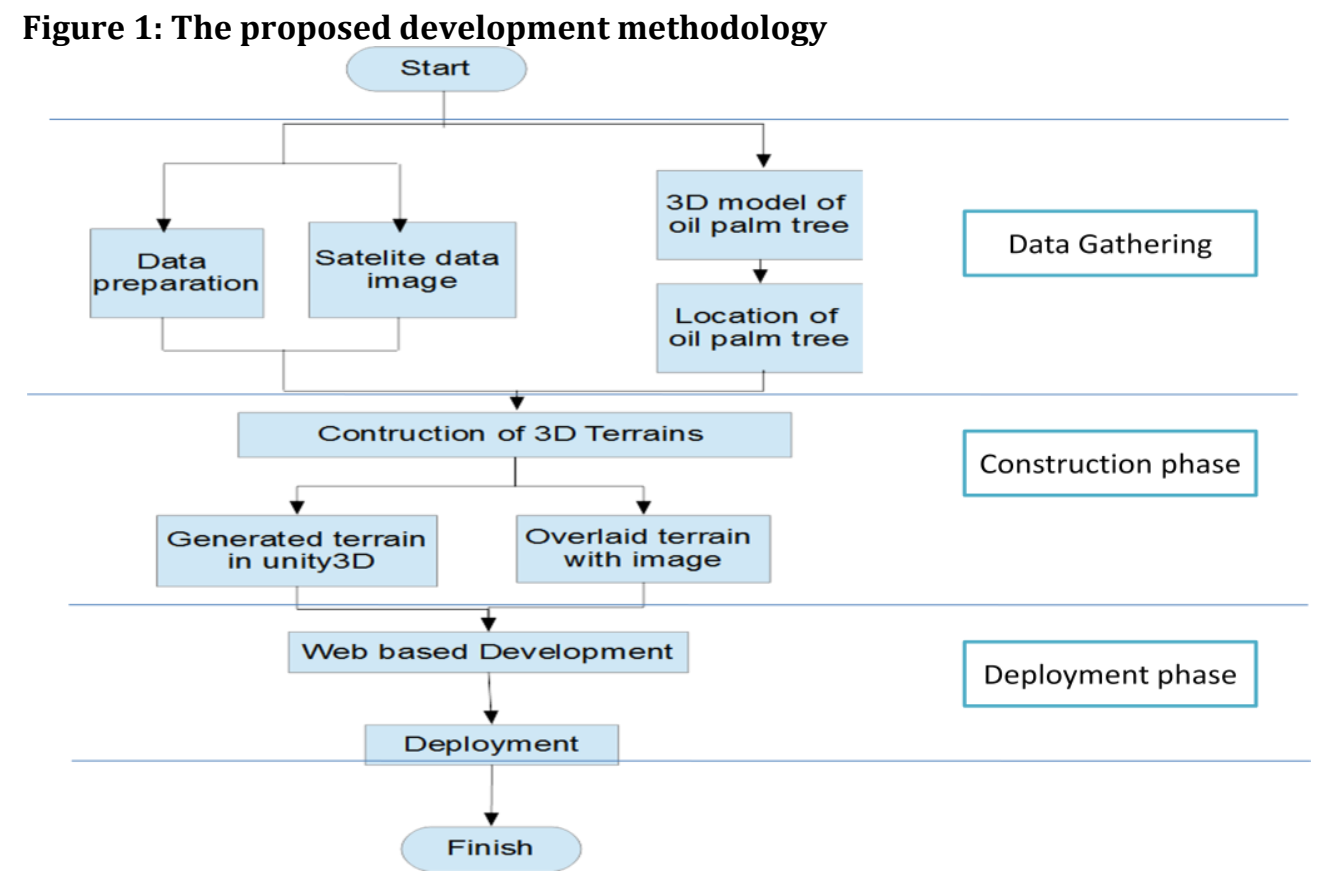

Data gathering phase is divided into two parts which are terrain and imagery data preparation and modeling of oil palm tree complete with its location and coordinate. These phases are crucial because the development of online 3D application depends totally input of this phase. If the input is not properly processed, the output of the system was unuseful. During the construction phase, the real 3D terrain was generated based on the input of data gathering phase. The process involved in this phase includes setting the terrain data in the proper place for displaying it in the correct position. Lighting and camera setting involved in this stage to smoothly displaying the terrain. By utilizing the scripting, the correct coordinate conversion could be properly implemented. Besides that, the user interface of the system also could be set up according to the users' needs. The terrain can be generated into two forms which is overlaid with imagery or not overlaid with imagery. Walk through capability also could be programmed accordingly to help users in exploring the terrain. The placement of 3D oil palm tree was made on top of 3D terrain with the correct coordinate. Finally, the system was converted into the web based format and ready to be proceed to the deployment phase. The final phase was deployment phase. In this phase, the system of online 3D application is being set up to be publishing onto the web. The HTML coding is used and editing is performed to ensure that the system were displayed properly when its deploy onto the web server. The system needs to be tested before it can be deployed. If the test is not satisfied, refinement needs to be made to get the best results. Then the system was launched into the proper place which as chosen by the developer. 


\section{Discussion}

The review on plant diseases and techniques in managing oil palm plantation towards a digitalized online 3D application has been introduced since 1997. Figure 2.0 shows the timeline for a review of plant disease involved in managing oil palm plantation. Based on literacy study, they are eight types of plant disease commonly detected in an oil palm plantation which are Root System Detection, Red Ring Disease (RRD), Basal Stem Rot (BSR), Basal Root Rot (BRR), Characteristic of matured oil palm tree, Nutrient Defficiencies Disease, Orange Spotting (OS) / Genetic Orange Spotting (GOS), and Leaves Nutrient Disease.

Figure 2: The timeline for review on plant disease in managing oil palm plantation towards a digitalized online 3D application

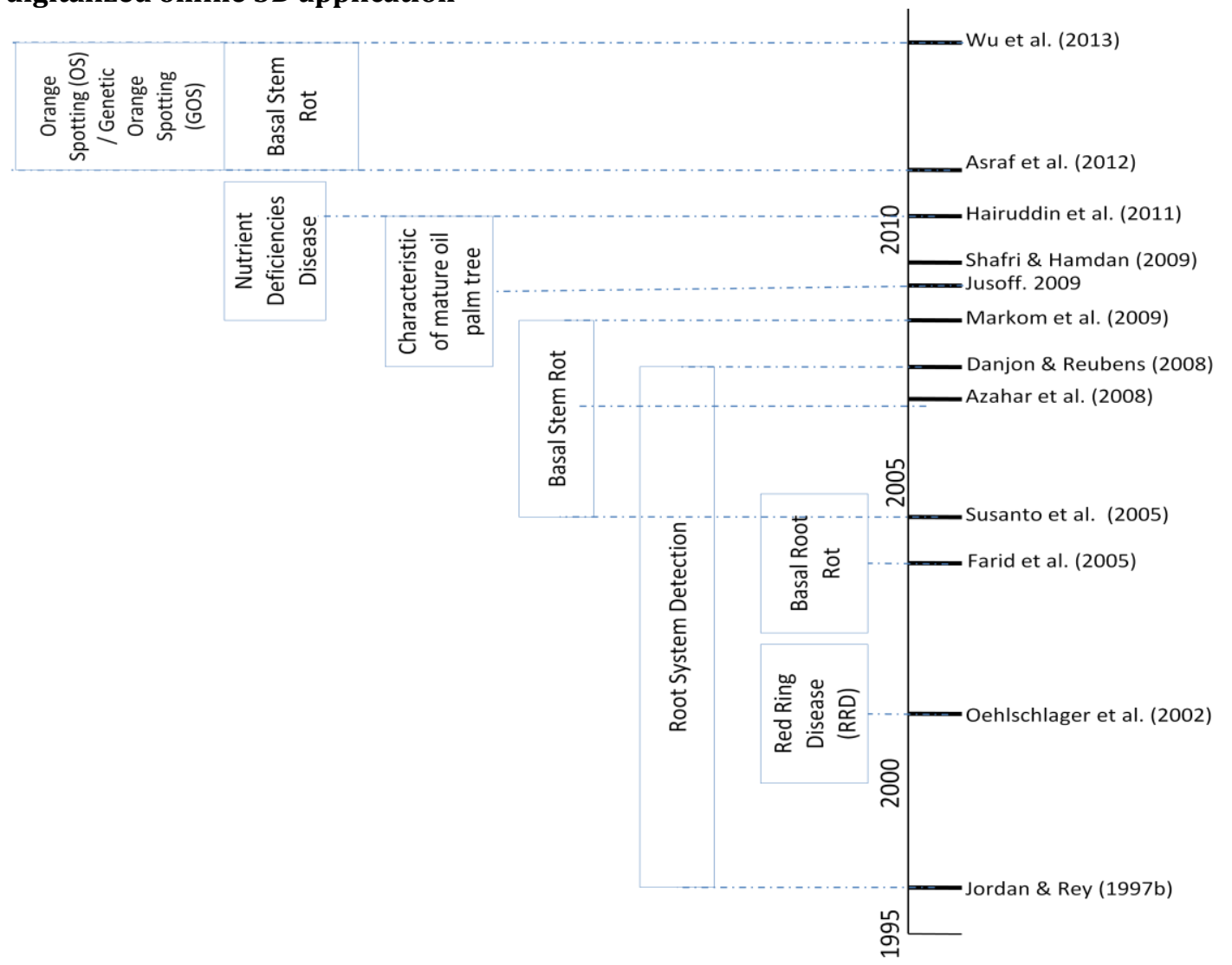

Table 1 shows a review of plant disease and technique in managing oil palm plantation towards a digitalized online 3D application. In the constructing of online 3D visualization technique for oil palm plantation a lot references have been studied and these references have contributed a lot in the construction process of online 3D visualization technique for oil palm plantation. In determining how long the old oil palm tree has been grown, Jourdan \& Rey (1997a) have introduced new techniques to measure the root system characteristic of 1-20 year years old oil palm tree root. Dungeon \& Reubens (2008) use 3D Visualization technique to detect oil palm tree Root System. While Jusoff (2009) have introduced the technique on how to identify characteristics of the matured oil palm tree using 3D modeling and airborne remote sensing data. This research also covered on the diseases that have commonly attacked the oil palm tree.

In terms of oil palm tree diseases, there are many research involves by many researchers to introduce new techniques of detecting some of the common disease normally infected by oil palm tree. For example, Oehlschlager et al. (2002) have done research on detecting Red Ring disease using manual periodical visual surveys to find which oil palm tree that is infected. Farid et al. (2005) have found the technique on how to find Basal Root Rot (Tectona Grandis) by using Pathogenicity Experiment Test. The other disease related to the oil palm tree was Basal Stem Rot (BSR). This disease is caused by the Ganoderma Boninense fungus as found by Susanto et al. (2005) in his research which uses Biological Agent Control to detect these diseases. This is explained more in research done by Markom et al. (2009) which uses Intelligent Electronic Nose System to find the Ganoderma Boninense fungus. On the research done by Azahar et al. (2008) the detection of Basal Stem Rot can be done by using Geographical Information System (GIS). 
Different with Shafri \& Hamdan (2009) which done the research on finding the infected oil palm tree by using Airborne Hyperspectral Imagery. In recent years, new oil palm tree disease have been discovered, and this is explained more in research done by Hairuddin et al. (2011) where in the paper it is written that Nutrient Defficiencies Disease is recently found and uses Image segmentation and feature extraction to find the disease. Another disease that has also discovered by Wu et al. (2013) is Orange Spotting (OS) / Genetic Orange Spotting (GOS). This disease can be detected using Pathogenicity Experiment Test. Also research done by Asraf et al. (2012) discover new disease related to oil palm tree which called the Leaves Nutrient Disease. In this research, it uses System and Pattern Recognition using Support Vector Machine (SVM) to detect infected trees.

Table 1: The review of plant disease and technique in managing oil palm plantation towards a digitalized online 3D application

\begin{tabular}{|c|c|c|}
\hline Authors & Plant Disease & Techniques \\
\hline Jourdan \& Rey (1997b) & Root System Detection & $\begin{array}{l}\text { (3-D Architecture) Jourdan and Rey } \\
\text { (1997a) measured root system } \\
\text { characteristics in a } 1-20 \text { year-old oil } \\
\text { palm }\end{array}$ \\
\hline Oehlschlager et al. (2002) & Red Ring Disease (RRD) & Manual Periodic Visual Survey \\
\hline Susanto et al. (2005) & $\begin{array}{l}\text { Basal Stem Rot (BSR) disease } \\
\text { that is caused by Ganoderma } \\
\text { Boninense fungus }\end{array}$ & Biological Agent Control \\
\hline Farid et al. (2005) & $\begin{array}{l}\text { Basal Root Rot (Tectona } \\
\text { Grandis) }\end{array}$ & Pathogenicity Experiment Test \\
\hline Azahar et al. (2008) & Basal Stem Rot (BSR) disease & $\begin{array}{l}\text { Geographical Information System } \\
\text { (GIS) }\end{array}$ \\
\hline Danjon \& Reubens (2008) & Root System Detection & 3-D Visualization \\
\hline Shafri \& Hamdan (2009) & $\begin{array}{l}\text { Ganoderma Basal Stem Rot } \\
\text { disease }\end{array}$ & Airborne Hyperspectral Imagery \\
\hline Markom et al. (2009) & $\begin{array}{l}\text { Basal Stem Rot (BSR) disease } \\
\text { that is caused by Ganoderma } \\
\text { Boninense fungus }\end{array}$ & Intelligent Electronic Nose System \\
\hline Jusoff (2009) & $\begin{array}{l}\text { Characteristic of matured oil } \\
\text { palm tree }\end{array}$ & Airborne Remote Sensing \\
\hline Hairuddin et al. (2011) & Nutrient Defficiencies Disease & $\begin{array}{l}\text { Image segmentation and feature } \\
\text { extraction }\end{array}$ \\
\hline Wu et al. (2013) & $\begin{array}{l}\text { Orange Spotting (OS) / } \\
\text { Genetic Orange Spotting (GOS) }\end{array}$ & Pathogenicity Experiment Test \\
\hline Asraf et al. (2012) & Leaves Nutrient Disease & $\begin{array}{l}\text { System and Pattern Recognition } \\
\text { using Support Vector Machine (SVM) }\end{array}$ \\
\hline
\end{tabular}

\section{Conclusion}

A review on techniques in managing oil palm plantation towards a digitalized online 3D application has been successfully done. The proposed idea in enhancing the existing management technique to the digitizing management technique in the oil palm plantation areas was properly addressed. The proposed methodology for developing the online 3D applications also discussed. The advantages of the proposed system are that it can access online at anytime, anywhere, and any place which the users can explore the details of oil palm plantation in 3D environments. It therefore gives benefits to oil palm manager to explore and gain experience the 3D environment of oil palm plantation virtually and helps for better management practices.

\section{References}

Asraf, H. M., Nooritawati, M. T. \& Rizam, M. S. B. S. (2012). A Comparative Study in Kernel-Based Support Vector Machine of Oil Palm Leaves Nutrient Disease. International Symposium on Robotics and Intelligent Sensors, 41(Iris ), 1353 - 1359 
Azahar, T. M., Boursier, P. \& Seman, I. (2008). Spatial Analysis of Basal Stem Rot disease using Geographical Information System. Map Asia.

Azahar, T. M., Boursier, P. \& Seman, I. (2008). Spatial Analysis of Basal Stem Rot disease using Geographical Information System. Paper presented at the Map Asia 2008, Kuala Lumpur, Malaysia.

Danjon, F. \& Reubens, B. (2008). Assessing and analyzing 3D architecture of woody root systems, a review of methods and applications in tree and soil stability, resource acquisition and allocation. Plant and Soil, 303(1-2), 1-34.

Danjon, F., Sinoquet, H., Godin, C., Colin, F. \& Drexhage, M. (1999). Characterisation of structural tree root architecture using 3D digitising and AMAP mod software. Plant and Soil, 2, 241 - 258.

Fairhurst, T., Rankine, I., Kerstan, A. G., McAleer, V., Taylor, C. \& Griffiths, W. (2003). A Conceptual Framework for Precision Agriculture in Oil Palm Plantation. Oil Palm: Management for Large and Sustainable Yields. PPI-PPIC-IPI, 321-332.

Farid, A., M., Lee, S. S. \& Sciences, B. (2005). Basal Root Rot , A New Disease of Teak ( Tectona grandis ) in Malaysia caused by Phellinus noxius. Malaysian Journal of Microbiology, 1(2), 40 - 45.

Hairuddin, M. A. \& Mara, U. (2011). Representation of Elaeis Guineensis Nutrition Deficiency Based On Image Processing Approach. Paper presented at the International Conference on Computer Applications and Industrial electronics (ICCAIE).

Jalani, B. S., Basiron, Y., Darus, A., Chan, K. W. \& Rajanaidu, N. (2002). Prospects of Elevating National Oil Palm Productivity: A Malaysian Perspective. Oil Palm Industry Economic Journal, 2(2), 1-9.

Jourdan, C. (1997). Modelling and simulation of the architecture and development of the oil-palm (Elaeis guineensis Jacq .) root system II . Estimation of root parameters using the RACINES postprocessor. Plant and Soil, 190, 235 - 246.

Jourdan, C. \& Rey, H. (1997a). Architecture and development of the oil-palm (Elaeis guineensis Jacq.) root system. Plant and Soil, 189(1), 33-48.

Jourdan, C. \& Rey, H. (1997b). Modelling and simulation of the architecture and development of the oilpalm (Elaeis guineensis Jacq.) root system. Plant and Soil, 190(2), 235-246.

Jusoff, K. (2009). Sustainable Management of a Matured Oil Palm Plantation in UPM Campus, Malaysia Using Airborne Remote Sensing. Journal of Sustainable Development, 2(3), 195-200.

Lamanda, N., Dauzat, J., Jourdan, C., Martin, P. \& Malézieux, E. (2008). Using 3D architectural models to assess light availability and root bulkiness in coconut agroforestry systems. Agroforestry Systems, 72(1), 63-74.

Markom, M. A., Shakaff, A. Y. M., Adom, A. H., Ahmad, M. N., Hidayat, W. \& Abdullah, A. H. (2009). Intelligent Electronic Nose System for Basal Stem Rot Disease Detection. Computers and Electronics in Agriculture, 66(2), 140 - 146.

Ming, K. K. \& Chandramohan, D. (2002). Malaysia Palm Oil Industry at Crossroads and Its Future Direction. Oil Palm Industry Economic Journal, 2(2), 10-15.

Nelson, M. R., Orum, T. V., Jaime-Garcia, R. \& Nadeem, A. (1999). Applications of Geographic Information Systems and Geostatistics in Plant Disease Epidemiology and Management. Plant Disease, 83(4), $308-319$.

Oehlschlager, A. C., Chinchilla, C., Castillo, G. \& Gonzalez, L. (2002). Control of Red Ring Disease by Mass Trapping of Rhynchophorus Palmarum (Coleoptera: Curculionidae). [doi: 10.1653/00154040(2002)085 0507:CORRDB 2.0.C0;2]. Florida Entomologist, 85(3), 507-513.

Ruzinoor, C. M., Shariff, A. R. M., Mahmud, A. R., Pradhan, B. \& Rahim, M. S. (2010). Development of Online 3D Terrain for Oil Palm Plantation. Paper presented at the World Engineering Congress (WEC 2010), Kuching Sarawak, Malaysia.

Shafri, H. Z. M. \& Hamdan, N. (2009). Hyperspectral Imagery for Mapping Disease Infection in Oil palm plantation. American Journal of Applied Sciences, 6(6), 1031 - 1035.

Susanto, A., Sudharto, P. S. \& Purba, R. Y. (2005). Enhancing biological control of basal stem rot disease (Ganoderma boninense) in oil palm plantations. Mycopathologia, 159(1), 153 -157.

Wu, T. H., Bettadapura, D. P. \& Beal, P. E. (1988). A Statistical Model of Root Geometry. Forest Science, 34(4), 980-997.

Wu, Y. H., Cheong, L. C., Meon, S., Lau, W. H., Kong, L. L. \& Joseph, H. (2013). Characterization of Coconut cadang-cadang viroid variants from oil palm affected by orange spotting disease in Malaysia. Archives of virology, 1, 8 - 11. 